\title{
Nursing Students' Perception Regarding their Nursing Role
}

\author{
Fatma Rushdy Mohamed \& Samah Mohamed Abdalla
}

Assistant Professor of Nursing Administration,Faculty of Nursing, Assiut University, Egypt.

\begin{abstract}
:
A positive and enriched learning environment can influence a students' perception of the healthcare facility as a possible future employment site. The aim of the present study was to explore student nurses' perception regarding their nursing role. A descriptive design was used in the present study. This study was conducted at Faculty of Nursing-Assiut University. The study subjects constituted of 763 students who were enrolled in the $1^{\text {st }}(164), 2^{\text {nd }}$ (130), $3^{\text {rd }}(146), 4^{\text {th }}$ academic year (112) (2012-2013) at Faculty of Nursing-Assiut University, and (211) internship year respectively. The overall of the total nursing students' perceptions about their roles scale had an internal consistency of $\alpha=0.944$. Results: Mean scores were highest among the four academic years as regard to administration, care giver, communication, and teaching respectively. While, among internship year students care giver was the highest mean score followed by communication, administration and teaching respectively. There was a highly statistically significant difference for all factors among the four academic year and internship year (**P $\leq$ 0.001). Conclusions: Four academic years students perceived administration highest mean score followed by care giver, communication, and teaching as the main roles of nurses. While, among internship year students care giver was the highest mean score followed by communication, administration and teaching respectively with a highly statistically significant differences. Recommendations: Nurse Educators and practitioners are responsible for the development of nursing students' perception and working as a role model and interactions that provides the context for student learning and professional socialization. Researching how managers and senior leaders view the role of a nurse students would prove valuable in developing a strong and positive working relationship among nurse managers, staff nurses, nursing educators, and students.
\end{abstract}

Key Words: Perception - Nursing Students - Role.

\section{Introduction:}

Nursing is a human science and human care is always threatened and fragile. The image of both nurses and nursing as a profession are vital in the successful recruitment and retention of staff in the healthcare industry (Annelie, 2010). Waters believes that nurses are the backbone of the healthcare sector and are fundamental in the delivery of quality care for all the inhabitants of a country. Changes have taken place in the last two decades in the way health care is being delivered and managed; these changes consist of a different way of practice and perception of the profession. (Waters, 2005). Nursing Students come into nursing education with inherent lay beliefs of nursing that evolve over years of education, enabling them to be professionally socialized into the nursing career. Numerous factors, including curriculum, educators, clinical instructors, practicing nurses, family, peers, school or other institutions, the changing environment from a hospital to a community setting and the cultural setting form important input to the process of nursing students' professional identification (Cook et al. 2003; Papp et al. 2003 ;Day et al. 2005).

Mason- Whitehead et al., (2008) clarified that the concept 'nursing' is more than a definition. It is part of a particular group's framework of communication, their language, and, thus, a reflection of who nurses is. This definition also carries a person's perception. The Oxford English Dictionary (2010) defined perception as one's awareness and understanding of sensory information attained through interplay between past experiences, one's own culture and the interpretation of the perceived. Gregory, (2004) postulated that perception is conceived through a linear dynamic relationship between 'description' (in the brain), the senses and the surrounding. It is a bidirectional interplay that holds true to the linear concept of experience. Based on the reviewed literature (Manninen 1998; Ewens 2003), stated that perception of one's professional identity changes over the course of the 4 years of the nursing program. Being a nurse is not only about taking care of patients, but it also requires knowledge of technology, more paper work and more stringent standards of care. Another way nursing has been changing over the years is the gradual increase in men entering the profession and, thus, introducing a new nuance to the meanings embedded in the profession. Bearing on these imminent transformations, nurses and nursing educators are compelled to assist students in their development of caring, nurturing and critical thinking, and to acquire 
the latest introduction of technological advances into the healthcare system (Gramling \& Nugent 1998).

Nursing students spend a great deal of their training in the clinical learning environment to develop interpersonal skills and become socialized into the formal and informal norms and expectations of the profession. Not only do these students have to manage their learning tasks within the social context of the workplace, they also need to face the demands of the workplace environment, where they are required to accept responsibility for patient care according to their scope of practice (Mellish, et al., 1998; Quinn \& Hughes, 2007).

\section{Significance of the study}

Importance of student nurses to know their future roles to facilitate and prepare them socially to work and decrease the reality shock when go outside to the labor market. So, the researchers think that it is important to study student nurses' perception regarding their nursing roles at Faculty of Nursing Assiut University.

\section{Aims of the study}

The aim of the present study was to explore student nurses' perception about their nursing roles.

\section{Research questions}

1. What are the student nurses' perceptions regarding their roles?

2. Is there a change in internship students' perception regarding their nursing roles after graduation?

\section{Subject and Method}

Research design

A descriptive design was used to in the present study. I-Setting:

This study was conducted at Faculty of NursingAssiut University. Faculty of Nursing was built in 1982 as a Higher Institute of Nursing which followed the Faculty of Medicine then issued Presidential Decree number (200) of 2000 turned to be Faculty of Nursing. Now, It included eight departments as the following ; Department of Adult Nursing with total number of thirty one staff members; Department of Gynecology and Obstetric Nursing with total number of twenty two staff members; Department of Pediatric Nursing with total number of twenty one staff members; Psychiatric and Mental Health Nursing with total number of sixteen staff members; Nursing Administration Department with total number of fourteen staff members; Community Health Nursing Department with total number of seventeen staff members; Department of Geriatric Nursing with total number of eight staff members; and Department of Critical Care Nursing with total number of ten staff members. Faculty of Nursing included Fourteen Laboratory available for different specialties.

\section{II-Subjects}

The study sample constituted of 763 students. They are all student nurses who were enrolled in the first, second, third, and fourth academic year, (2012-2013) at Faculty of Nursing-Assiut University and internship students. They are classified as the following: $1^{\text {st }}(164), 2^{\text {nd }}(130), 3^{\text {rd }}(146), 4^{\text {th }}$ academic year (112), and internship year (211) respectively, their age ranged from 18 to 22 years.

\section{III- Tool of the study:}

- A self - administer questionnaire was developed by the researchers. It consisted of 68 items divided into four factors as the following: 28 items covered administration factor as: ( Maintain a calm department; Ensure that nurses colleagues performed the work required from them; Insure that her colleagues washing the equipments and sterilized it before use ; Ensure the safety of the equipments owned for the department ; Reviewing the inventory daily and monthly; Ensure the safety devices and blood pressure apparatus of the department ; Working on training the students that found the department ; Ensure that all resources recorded in the inventory record; Ensure that the resources are used in an economical and efficient ....etc.) ; 13 items covered communication factor as: (Your behavior should be ideal for other nurses; Maintain communication friendly with health care team; Calms the patient and ease his anxiety before the operation or any action ; Communicate verbally in a low voice with her colleagues, patient, and the doctors ;Communicate verbally with patients before doctor round and take the history of disease from the patient and write it in the patient record...etc.); 19 items covered care giver factor as: (Discuss patients on the progress of their condition; Keeps the patients records ; Assess the progress and status of patients ; Notify the doctor about the progress of patient's condition; Record of patients who transferred ; Implement procedures for the transfer of patients or discharge ; Change for immobilized patients every two hours; Provide assistance and advice to the relatives of patients.....etc); and $\mathbf{8}$ items covered teaching factor as: (Attending in training courses for upgrading of nursing competence ; Orient internship students about the system and how to work; Deals with nursing problems faced students by helping them in solving their problems and provide them advice ; Explains the doctor instructions for patients to ensure the patients implement of his instructions...etc). The possible responses of this part were five point Likert Scale: Strongly disagree scored (5), disagree scored (4), sometimes scored (3), agree scored (2), and strongly agree scored (1). Reliability of the tool was done and revealed that the tool is highly reliable $(\alpha=$ $0.944)$. The validity was measured by five experts in 
nursing administration to ensure content validity of the study tool.

\section{Iv. Administrative design}

An official permission was obtained from the dean of the Faculty of Nursing-Assiut University. Arrangements were done to avoid any delays or affection of the regular teaching/learning activities.

\section{Operational design}

This design explains the steps of actual implementation of the study, including preparatory phase, the pilot and the field work.

Preparation phase:-

This phase took about two months October and November 2012 and included the following:

1- Review the available literature concerning the topic of the study.

2- Prepare and translate of the study tool.

\section{Pilot study}

A pilot study was conducted to test the reliability, applicability and practicability of the questionnaire and detect the obstacles and problems that may be encountered during data collection. It also helped to estimate time needed to fill questionnaire. It was carried out on 20 students from second academic year and was excluded from the study sample. Data collected from the pilot study were reviewed prior to the final application of the study tool.

Field work

After ensuring the clarity of the study tool, the actual data collection from students' nurses was started. The data collection phase of the study took about two months December and January (2012- 2013). The researchers give each nurse student the study tool after explanation of the aim of the study. Each student took about $15-20$ minutes to fill the questionnaire.

\section{Vi. Statistical Design}

Upon completion of data collection, data entry was done using Epi-Info 6.04 computer software package, while statistical analysis was done using SPSS 16.0 statistical software packages. Data were presented using descriptive statistics in the form of means and standard deviations for quantitative variables.

\section{Results:}

Table (1): Reliability of nurses' perception about their roles scale factors as measured by internal consistency

\begin{tabular}{|l|c|c|}
\hline \multicolumn{1}{|c|}{ Factor } & Number of items & Cronbach alpha coefficient \\
\hline Administration & 28 & 0.878 \\
\hline Communication & 13 & 0.835 \\
\hline Care giver & 19 & 0.795 \\
\hline Teaching & 8 & 0.723 \\
\hline Total reliability of the scale & $\mathbf{4}$ (factors) & $\mathbf{0 . 9 4 4}$ \\
\hline
\end{tabular}

Figure (1): Mean scores of faculty of nursing students perception about their roles

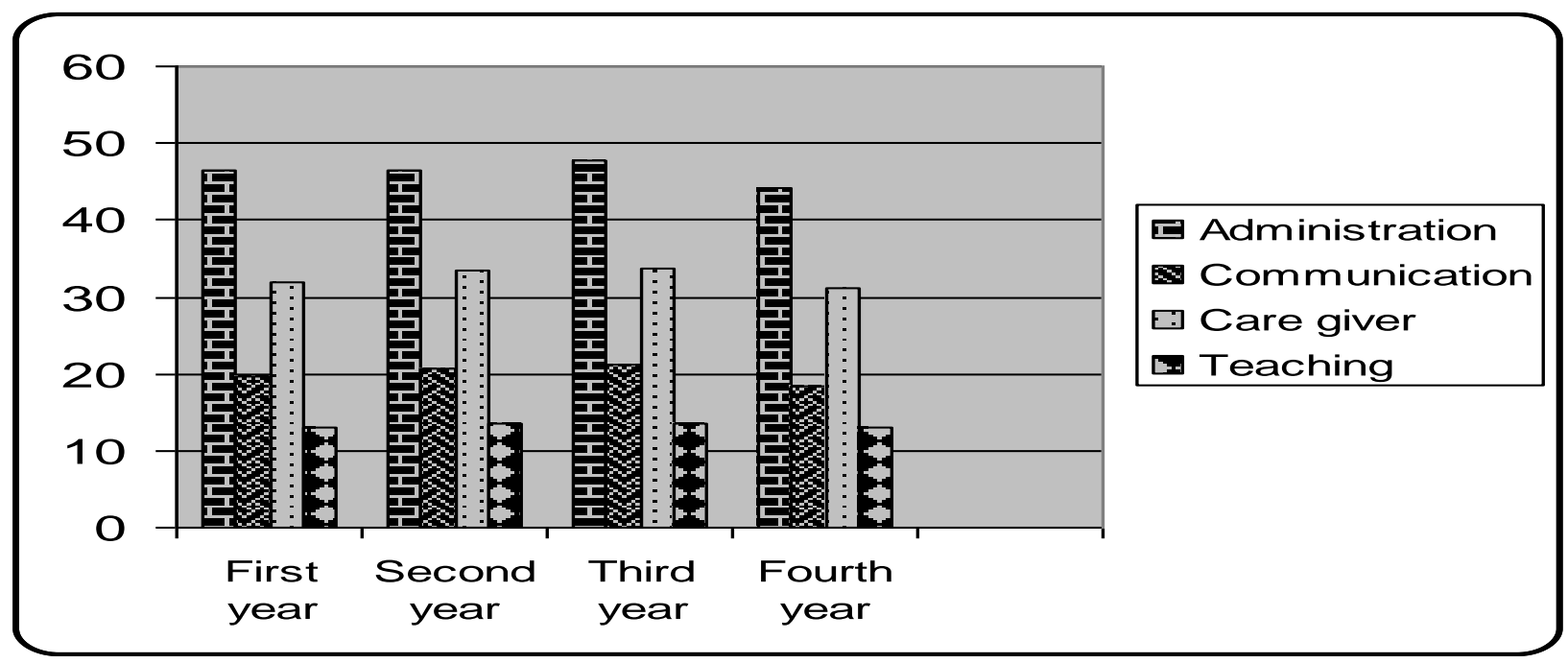


Figure (2): Mean scores of internship nursing students' perception about their roles.

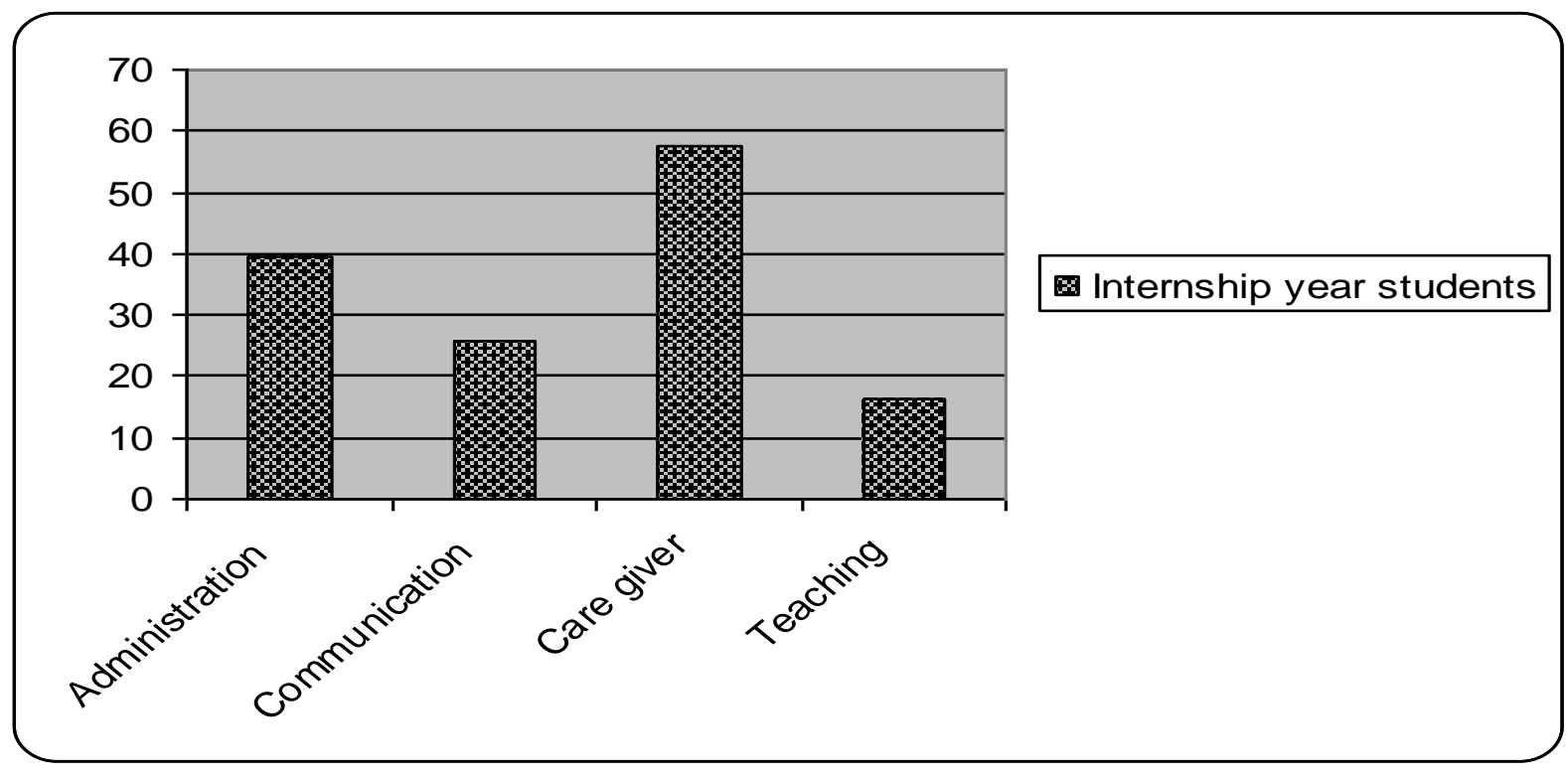

$* * P \leq 0.001$

Table (1): Illustrates the results of assessment of the reliability of the nursing students' perceptions about their roles scale, by measuring its internal consistency using Cronbach's alpha coefficient method. As the table shows, all the coefficients were high, exceeding 0.80 . The overall of the total nursing students' perceptions about their roles scale had an internal consistency of $\alpha=0.944$.

Figure (1): Demonstrates that mean scores were highest among the four academic years as regard to administration, care giver, communication, and teaching respectively. There was a highly statistically significant differences for all factors among the four academic year $(* * \mathrm{P} \leq 0.001)$.

Figure (2): Displays that among internship year students care giver was the highest mean score followed by communication, administration and teaching respectively. There was a highly statistically significant differences for all factors among internship year students $\left({ }^{* *} \mathrm{P} \leq 0.001\right)$.

\section{Discussion:}

During the course of the 4 years of the studying program, nursing students' perception of nursing developed from a traditional altruistic view of the profession to a more biomedical, technological one. Students' perceptions were influenced by the educational program's stages and this underwent three prominent phases: the traditional views at entry; the influence of nursing theory and science; and the influence of the clinical experience that remained stable until graduation. Beginners' traditional altruistic perceptions of nursing is in agreement with studies in the West where nurses at entry described nursing in terms of caring, comforting and healing (Cook et al. 2003) and altruistic humanitarian conviction with lay terms of love and care (Day et al. 2005).

The results of the present study (figure, 1) shows that nurse roles factors were in the following sequences administration, care giver, communication, and teaching respectively as regard four faculty academic years. Mason-Whitehead et al. (2008) were inconsistent with the present study results who pointed that today's nursing faculty's' curricula are designed with particular emphasis on caring concepts and description of emotional and behavioral responses that draw on technical and interpersonal knowledge and skills.

However, other classic western studies indicated that students' perceptions progressed from lay beliefs to perceptions of patients in phases of illness as in the primary, secondary and tertiary settings, and as more than physical malfunctioning, which is a stronger professional image of nursing (Cook et al. 2003).

In addition, Bolan \& Grainger, (2009) indicated that students maintain some traditional beliefs from year one to year four. The concepts that demonstrated this stable perception of the profession were highly appreciative of cultural beliefs, evolving around nursing as tasks and altruistic 'catch phrases' of nursing science and arts. The third and last stage in students' developing perceptions appeared soon after exposure to clinical settings, that is, after the second semester of the second year of the program. During 
the last 2 years, courses are more specialized and focused on clinical applications. This is when students were in direct contact with patients, other healthcare professionals and the community at large. In these settings, students began to perceive nursing from a wider perspective, away from the nursing faculty and their teachers in theory classes.

As shown in Figure, (2) internship year students had highest mean score in care giver followed by communication, administration and teaching respectively. These may be attributed to most internship students training areas were in intensive care units followed by communication as most of them view nursing as independence. This may be attributed that when students became away from faculty for longer periods, practicing nurses became their role models, and the hospital environment replaced their faculty's familiar setting. Perceptions have changed from the idealistic views of nursing gained from the faculty of nursing to what is actually existent in a practice setting.

Andersson, (1993) demonstrated the theory-practice gap described the difference between what students were taught as ideal and what they have observed in clinical practice in hospitals. In addition, ApesoaVarano, (2007) explained this theory- practice gap as a form of burnout, where 'caring' loses its attractiveness and motivating force, leading to a negative development and construction of an identity based on 'educated caring'. How this gulf between the academic and the clinical settings can be bridged remains an important enigma warranting further intervention.

Moreover, Pearcey , (2007) demonstrated that contrary to the faculty's aims of graduating nurses with a holistic view of nursing care, students developed a more technical, biomedical approach. Changing focus of care from caring to carry out procedures is an outcome commonly found in nursing practice. In today's biomedical, technological environment, nurses, like other health professionals, are more interested in new trends and medical technology. He indicating that despite 'newer' trends in nursing that advocated a move away from tasks and routines, and independence from the medical model; 'holism' remains a term that is followed by a list of physical tasks, with no indications that this term is really understood by students.

\section{Conclusions:}

In the light of the study results, the following conclusions can be drawn:

Four academic years students perceiving administration, care giver, communication, and teaching were the main roles respectively. While, among internship year students care giver was the highest mean score followed by communication, administration and teaching respectively with a highly statistically significant differences.

\section{Recommendations:}

Based on the forgoing conclusions, the following recommendations are proposed:

- Nurse educators and practitioners are responsible for the development of nursing students' perceptions and working as a role model and interactions that provides the context for student learning and professional socialization.

- Implications for further study include an exploration of factors that may stimulate retention of desired perceptions and values gained through academic years and ultimately displayed in practice.

- Researching how managers and senior leaders view the role of a nurse students would prove valuable in developing a strong and positive working relationship among nurse managers, staff nurses, nursing educators, and students.

\section{References:}

1. Andersson, E. (1993): The perspective of student nurses and their perceptions of professional nursing during the nurse training program. Journal of Advanced Nursing, 18 (5), 808-815.

2. Annelie, M (2010): The image of nurses as perceived by the south African public, A dissertation submitted in fulfillment of the requirements for the degree of Master in the Department of Nursing Science, Faculty of Health Sciences, University of Pretoria, 2010

3. Apesoa-Varano, E. (2007): Educated caring: the emergence of professional identity among nurses. Qualitative Sociology, 30 (3), 249-274.

4. Bolan, C. \& Grainger, P. (2009): Students in the BN program - Do their perceptions change? Nurse Education Today, 29 (7), 775-779.

5. Cook, T., Gilmer, M. \& Bess, C. (2003): Beginning students' definitions of nursing: an inductive framework of professional identity. The Journal of Nursing Education, 42 (7), 311317.

6. Day, A., Field, P., Campbell, I. \& Reutter, L. (2005): Students' evolving beliefs about nursing: from entry to graduation in a four-year baccalaureate program. Nurse Education Today, 15, 357-364.

7. Ewens, A. (2003): Changes in nursing identities: supporting a successful transition. Journal of Nursing Management, 11, 224-228. 
8. Gramling, L. \& Nugent, K. (1998): Teaching caring within the context of health. Nurse Educator, 23 (2), 47-51.

9. Gregory, R. (2004): Perception, volume 33, pages 895-896 from Perception. Available at: http://en.wikipedia.org/wiki/Perception (accessed 21 Dec 2010).

10. Manninen, E. (1998): Changes in nursing students' perceptions of nursing as they progress through their education. Journal of Advanced Nursing, 27 (2), 390-398.

11. Mason-Whitehead, E., McIntosh, A., Bryan, A. \& Mason, T. (2008): Key Concepts in Nursing. Sage, Los Angeles.

12. Mellish, J; Brink, H \& Paton, F. (1998): Teaching in practice of nursing. Jonannesburg, Heinemann.

13. Papp, I., Markkanen, M. \& von Bonsdorff, M. (2003): Learning environment: student nurses' perceptions concerning clinical learning experiences. Nurse Education Today, 23, 262268.

14. Pearcey, P. (2007): Tasks and routines in $21 \mathrm{st}$ century nursing: student nurses' perceptions. British Journal of Nursing, 16 (5), 296-300.

15. Quinn, F. \& Hughes, S. (2007): Quinn's principles and practice of nursing education. $5^{\text {th }}$ edition, Cengage learning publisher, Australia.

16. The Oxford English Dictionary, (2010): Oxford dictionaries online. The World's Most Trusted Dictionaries. Available at: http://www.oxforddictionaries. com/definition/ perception ?View=uk (accessed 21 December 2010).

17. Waters, A. (2005): Nursing is the most emotionally rewarding career. Nursing Standard, 19(30): 22-26. 